\title{
ANALYSIS OF THE RELATIONSHIP BETWEEN TRAINING EXPERIENCE AND VISUAL SENSORY FUNCTIONS IN ATHLETES FROM DIFFERENT SPORTS
}

\author{
PIOTR LESIAKOWSKIIA, WOJCIECH LUBIŃSKI'1B, TERESA ZWIERKO² \\ 1Pomeranian Medical University in Szczecin, Faculty of Medicine, Department of Physical Education \\ and Sport ${ }^{a}$, Chair and Clinic of Ophthalmology ${ }^{b}$ \\ 2University of Szczecin, Faculty of Physical Culture and Health Promotion, \\ Chair of Kinesiology and Team Sports
}
Mailing address: Piotr Lesiakowski, Pomeranian Medical University in Szczecin, Department of Physical Education and Sport, 6a Dunikowskiego Street, 70-123 Szczecin, tel.: +48 91 4414511, fax: +48 914800705 , e-mail: lesiakowskipiotr@gmail.com

\begin{abstract}
Introduction. Gaining insight into the mechanisms and scope of possible adaptations of visual functions to the conditions determined by the demands imposed by sports training seems to be very interesting not only from a cognitive point of view, but also with respect to the practical applications of the findings of such investigations in the training process. The aim of the study was to assess the function of early visual processing in athletes representing different sports disciplines with varying training experience. Material and methods. The study involved 95 athletes practising football $(\mathrm{n}=24)$, volleyball $(\mathrm{n}=22)$, boxing $(\mathrm{n}=26)$, and rowing $(\mathrm{n}=23)$. The bioelectric function of the visual pathway was assessed based on recordings of visual evoked potentials (VEPs). The regions which were stimulated were the peripheral and central areas of the retina. During the test, we recorded the amplitude $(\mu \mathrm{V})$ and latency $(\mathrm{ms})$ of the P100 component of the VEP waveform for both monocular stimulation (for the dominant and non-dominant eye) and binocular stimulation. Results. Lower VEP P100 amplitude values were found for the peripheral and central locations for monocular and binocular viewing in more experienced volleyball players and rowers $(\mathrm{p}<0.05)$. In the case of boxers with greater training experience, a significantly lower $(\mathrm{p}<0.05)$ amplitude of the VEP P100 wave was observed in the central location in the dominant eye. However, we did not find significant differences $(p>0.05)$ in intragroup variability in VEP P100 latency in relation to training experience in any of the sports disciplines examined. Conclusions. Training experience has an influence on the early stage of sensory processing with respect to neural activity. Training experience has been found to differentiate athletes in terms of the temporal parameters of the visual evoked potentials recorded in the current study only to a limited extent.
\end{abstract}

Key words: visual evoked potentials, neural conductivity, sports training

\section{Introduction}

It is important for research which analyses the determinants of visual perception in sports to investigate the mechanisms of the adaptation of visual functions to the demands imposed by sports training. Based on the results of previous research, it can be predicted that sporting achievements can be aided by neuroplastic changes which take place already at an early stage of sensory processing. For example, Jin et al. [1] explored the amplitude and latency of the $\mathrm{Cl}$ potential, which is an electrophysiological indicator of primary visual cortex activity, in subjects watching video clips of motor actions in badminton. Their study showed that the amplitude of the $\mathrm{Cl}$ potential was significantly higher in professional athletes compared to non-athletes, whereas $\mathrm{Cl}$ latency was comparable in the two groups. The authors suggested that early sensory processing can be modulated by the performance of systematic sports training which requires rapid detection of and reaction to visual stimuli. Zwierko et al. [2], on the other hand, observed a significant reduction in signal conductivity time recorded at the level of the primary visual cor- tex over a two-year period of sports training in volleyball. Considerable changes were also found in visual processing after the stimulation of the peripheral area of the retina. The results of this study suggest that the specificity of the training in volleyball impacted the modulation of early sensory processing. Moreover, earlier research by Dustman et al. [3] revealed a significant increase in the sensory sensitivity threshold assessed using critical flicker frequency, related to greater activity of the visual cortex, after four months of aerobic exercise.

One of the methods of assessing early visual processing is analysing visual evoked potentials (VEPs). They are used to diagnose the function of the visual pathway and investigate the cortical mechanisms of visual processing [4]. A normal recording of VEPs reflects the functional integrity of the visual pathway from the retina to the areas of the visual cortex. VEPs are characterised by the following three waves: N75, P100, and N135. The N75 wave is known to originate in the primary visual cortex (Brodmann's area 17) [5]. The source of the P100 wave, which is considered to be the best diagnostic indicator of VEP, has not yet been unequivocally established: P100 is believed to 
be generated in the primary [5] or secondary visual cortex areas (Brodmann's areas 18 and 19) [6]. As far as the N135 wave is concerned, it has its origin in the secondary cortex [4].

The results of some experimental studies have confirmed that the components of visual evoked potentials differ in professional athletes compared to untrained individuals. The research by Thomas et al. [7] showed that cricket players had a shorter N75 wave latency than untrained subjects, whereas Delpont et al. [8] observed a shorter latency of P100 waves in tennis and squash players compared to rowers and control subjects. Similar results were obtained in studies involving athletes practising such sports as volleyball [9, 10], fencing [11], and karate [12]. These findings suggest that practising sports which are fastpaced and require accurate and rapid responses to visual stimuli can have a greater impact on the effectiveness of visual processing compared to undertaking other forms of sports training. However, these conclusions have not been confirmed by all of the research studies carried out in this respect. For example, Zhao et al. [13] found a reduction in P100 latency after 6-week cycloergometric exercise training, 8-week tennis training, as well as 6-week aerobic exercise training.

Thus, the research findings cited above to not provide a definite answer as to the degree to which the functions of early visual processing discussed in this article are related to the specificity of the sports training undertaken, the performance of any kind of sporting activity, or variation in individual predispositions. In order to explore these issues, we have examined the visual evoked potentials among the representatives of different sports disciplines with varying training experience. We hypothesised that variability in the bioelectric function in the visual pathway for the central and peripheral locations in monocular and binocular viewing is interrelated with the perceptual requirements stemming from the specificity of the sporting activity performed, and this function is more effective in athletes with greater training experience.

\section{Material and methods}

The study included 95 competitive athletes practising the following sports: football $(\mathrm{n}=24)$, volleyball $(\mathrm{n}=22)$, boxing $(n=26)$, and rowing $(n=23)$. These sports disciplines were selected based on the classification proposed by Williams [14] and Erickson [15]. They have categorised sports disciplines according to the degree of the involvement of visuo-perceptual functions based on such criteria as, among others, central fixation on moving objects, peripheral vision, multidirectional spatial localisation, fixation time, visual field size, contrast sensitivity, or eye alignment. Considering these criteria, the sports which are characterised by the highest level of perceptual skills, in descending order, would be football, volleyball, boxing, and rowing. The other important criterion for participant selection in the current study was the athletes' skill level. The participants were chosen from among highly skilled athletes, most of whom were medallists of Polish Championships, European Championships, and World Championships (boxing and rowing), and players playing in top-league teams (football and volleyball). Table 1 shows the basic descriptive characteristics of the participants in each of the groups.

All the participants had normal visual function, measured using basic parameters. The athletes who were qualified for the study had normal distance visual acuity or 1.0 (10/10), refractive errors from -1 to +1 dioptres, astigmatism up to 0.5 dioptre, intraocular pressure not exceeding $21 \mathrm{mmHg}$ (norm), and normal anterior and posterior segments of the eye. Colour dis-
Table 1. Descriptive statistics $(\bar{x} \pm \mathrm{SD})$ concerning the physical features, training experience, and training loads of the groups of athletes examined in the study

\begin{tabular}{|c|c|c|c|c|c|}
\hline Group & $\begin{array}{c}\text { Age } \\
\text { (years) }\end{array}$ & $\begin{array}{c}\text { Height } \\
(\mathrm{cm})\end{array}$ & $\begin{array}{c}\text { Weight } \\
(\mathrm{kg})\end{array}$ & $\begin{array}{c}\text { Training } \\
\text { experience } \\
\text { (years) }\end{array}$ & $\begin{array}{c}\text { Mean weekly } \\
\text { training load } \\
\text { (h/week) }\end{array}$ \\
\hline Football & $20.25 \pm 1.91$ & $181.04 \pm 7.29$ & $73.93 \pm 7.39$ & $6.54 \pm 2.96$ & $12-13$ \\
\hline Volleyball & $21.92 \pm 2.11$ & $194.06 \pm 6.22$ & $84.92 \pm 7.04$ & $8.14 \pm 1.31$ & 12 \\
\hline Boxing & $20.16 \pm 1.84$ & $173.41 \pm 5.16$ & $61.51 \pm 6.05$ & $6.03 \pm 3.22$ & $11-12$ \\
\hline Rowing & $21.83 \pm 1.86$ & $185.89 \pm 5.81$ & $82.36 \pm 12.41$ & $6.82 \pm 3.48$ & $15-16$ \\
\hline
\end{tabular}

crimination was tested using Ishihara plates. All the tests were performed at the Chair and Clinic of Ophthalmology at the Pomeranian Medical University in Szczecin.

The subjects gave written consent to participating in the study and were given detailed information concerning the research procedure. The study was approved by the Bioethics Committee of the Regional Medical Chamber in Szczecin.

The bioelectric function of the visual pathway was assessed by means of visual evoked potentials (VEP). These were recorded using the Reti Scan system (Roland, Germany). Retinal stimulation was assessed using black-and-white checkerboard reverse patterns, displayed on the screen with an alternation rate of $1.5 \mathrm{~Hz}$. The subjects were to fixate on the red cross located in the centre of the screen. The distance between the subjects' eyes and the screen was 1 metre. The tests were performed using surface electrodes which were positioned on the head according to the so-called 10-20 system (Jasper 1958). The impedance of the electrodes did not exceed $5 \mathrm{kOhm}$. Two types of stimulation were applied: the first one involved using checks of greater size $\left(1^{\circ} 4^{\prime}\right)$, stimulating the peripheral areas of the retina, that is the peripheral location (VEPL), and the second one involved the use of smaller checks $\left(0^{\circ} 16^{\prime}\right)$, stimulating the central area of the retina, that is the central location (VEPS). Each measurement was performed based on an average of 200 responses. During the test, the amplitude $(\mu \mathrm{V})$ and latency $(\mathrm{ms})$ of the P100 component of the VEP waveform were registered. Visual evoked potentials were recorded first for monocular stimulation (for the dominant and non-dominant eye) and then for binocular stimulation. A sample recording of the VEP waveform in shown in Figure 1. The tests were conducted in compliance with the

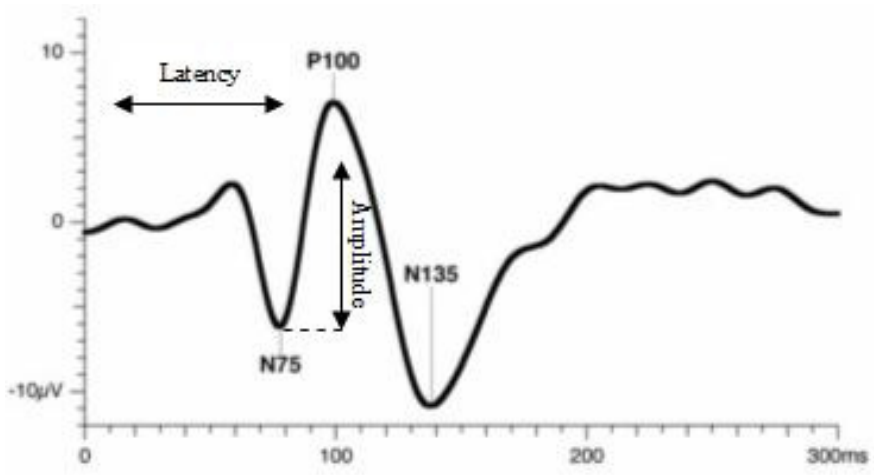

Figure 1. Sample visual evoked potential (VEP) waveform recorded in a resting state, with a description of the amplitude and latency of the positive deflection (P100 wave), as the most effective diagnostic indicator of VEP, and the negative deflections (N75 and N135 waves) 
standards for electrophysiological research established by the International Society for Clinical Electrophysiology of Vision [16].

The data were first analysed descriptively using commonly applied statistical methods in order to assess whether they were normally distributed. The following basic statistical measures were calculated: the mean, the standard deviation, the maximum and minimum values, and the coefficient of variation. Normality of distribution was tested using the Kolmogorov-Smirnov test. Since the data did not deviate considerably from normal distribution, parametric tests were used in subsequent analyses. In each of the groups of athletes practising a particular sport, the subjects were divided into two subgroups based on their training experience, that is the duration of systematic sporting activity, using the median (less experienced: $<=$ median vs. more experienced: > median). The median for training experience was calculated separately for each of the sports disciplines. The differences between the results achieved by more and less experienced athletes were analysed using Student's t-test.

\section{Results}

\section{P100 wave amplitude}

The analysis of the results of the study indicated that in some cases, there was a relationship between training experience and the amplitude of the P100 wave of the visual evoked potentials. In all of the sports disciplines examined in the study, more experienced athletes were characterised by a lower amplitude of this parameter, regardless of the type of stimulation and the viewing conditions during the tests.

The results obtained for the P100 wave of the visual evoked potentials with respect to training experience are presented in Table 2. A comparative analysis of the means showed that P100 amplitude was significantly lower ( $\mathrm{p}<$ $0.05)$ for the dominant eye in the central location in boxers with greater training experience $(4.949 \pm 2.115 \mu \mathrm{V})$ than in the other athletes practising this sport $(6.815 \pm 2.207 \mu \mathrm{V})$.

In the case of rowers, a lower P100 amplitude was observed for more experienced subjects in all viewing conditions for the peripheral location. In the assessment of the dominant eye in athletes with less training experience, the mean value of this parameter was $5.849 \pm 1.854 \mu \mathrm{V}$, whereas in those with more training experience, it amounted to $3.838 \pm 1.155 \mu \mathrm{V}$. The difference, which was equal to $2.011 \mu \mathrm{V}$, was statistically significant at the level of $\mathrm{p}<0.05$. Similarly, a lower value of the amplitude of the P100 wave was found in more experienced rowers based on the analysis of the recordings for the non-dominant eye (5.475 \pm $1.369 \mu \mathrm{V}$ vs. $3.936 \pm 1.292 \mu \mathrm{V} ; \mathrm{p}<0.05)$ and for binocular viewing $(5.597 \pm 1.726 \mu \mathrm{V}$ vs. $3.787 \pm 1.309 \mu \mathrm{V} ; \mathrm{p}<0.05)$. The analysis of the results of the two subgroups of rowers with respect to differences in the P100 amplitude in the central location showed that for non-dominant eye stimulation, more experienced athletes $(3.554 \pm 1.663 \mu \mathrm{V})$ also had significantly lower values of this parameter than those with less experience in rowing $(5.748 \pm 2.430 \mu \mathrm{V})$. Figure 2 shows the individual results for the amplitude of the P100 wave of the visual evoked potentials in the group of rowers for the non-dominant eye viewing condition in the central and peripheral locations.
In the group of volleyball players, the analysis of the differences between the two subgroups of subjects with varying training experience similarly revealed that more experienced athletes were characterised by lower results in the P100 amplitude for dominant eye

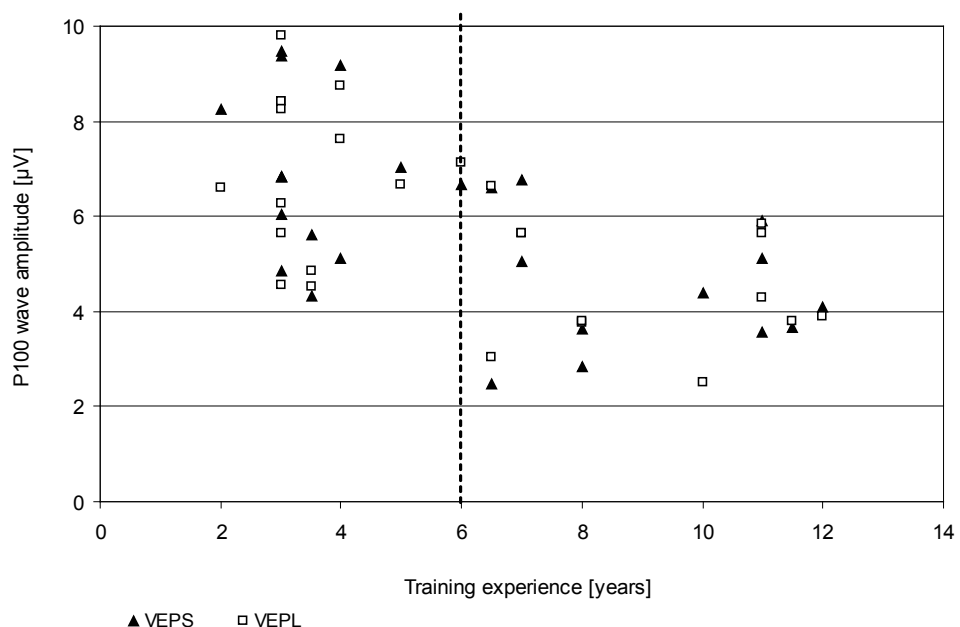

Figure 2. Results for the VEP P100 wave amplitude with respect to training experience in the group of rowers in non-dominant eye viewing for the central (VEPS) and peripheral (VEPL) locations

Table 2. Results for the VEP P100 wave amplitude $[\mu \mathrm{V}]$ with respect to training experience in the groups of athletes examined in the study

\begin{tabular}{|c|c|c|c|c|c|}
\hline $\begin{array}{l}\text { Disci- } \\
\text { pline }\end{array}$ & $\begin{array}{l}\text { Type of } \\
\text { stimula- } \\
\text { tion }\end{array}$ & $\begin{array}{l}\text { Viewing } \\
\text { conditions }\end{array}$ & $\begin{array}{c}\text { Less } \\
\text { experience } \\
\overline{\mathbf{X}} \pm S D\end{array}$ & $\begin{array}{c}\text { More } \\
\text { experience } \\
\overline{\mathbf{X}} \pm \text { SD }\end{array}$ & $\begin{array}{l}\text { Stu- } \\
\text { dent's } \\
\text { t-test }\end{array}$ \\
\hline \multirow{6}{*}{$\begin{array}{l}\overline{\overline{\bar{\sigma}}} \\
\text { 苂 } \\
\text { ४ }\end{array}$} & \multirow{3}{*}{$\begin{array}{c}\text { Peripheral } \\
\text { location }\end{array}$} & Dominant eye & $6.368 \pm 2.017$ & $5.605 \pm 1.809$ & -0.975 \\
\hline & & Non-dominant eye & $6.765 \pm 2.278$ & $5.466 \pm 1.812$ & -1.544 \\
\hline & & Binocular viewing & $7.324 \pm 2.618$ & $6.100 \pm 2.053$ & -1.274 \\
\hline & \multirow{3}{*}{$\begin{array}{l}\text { Central } \\
\text { Iocation }\end{array}$} & Dominant eye & $6.301 \pm 4.096$ & $5.000 \pm 1.755$ & -1.011 \\
\hline & & Non-dominant eye & $6.063 \pm 3.660$ & $5.137 \pm 1.711$ & -0.793 \\
\hline & & Binocular viewing & $6.735 \pm 5.606$ & $6.455 \pm 2.016$ & -0.162 \\
\hline \multirow{6}{*}{ 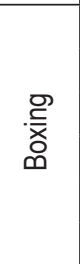 } & \multirow{3}{*}{$\begin{array}{c}\text { Peripheral } \\
\text { location }\end{array}$} & Dominant eye & $6.488 \pm 2.134$ & $4.998 \pm 1.902$ & -1.972 \\
\hline & & Non-dominant eye & $6.296 \pm 2.092$ & $5.000 \pm 1.687$ & -1.804 \\
\hline & & Binocular viewing & $6.952 \pm 2.507$ & $5.700 \pm 1.847$ & -1.488 \\
\hline & \multirow{3}{*}{$\begin{array}{l}\text { Central } \\
\text { location }\end{array}$} & Dominant eye & $6.815 \pm 2.207$ & $4.949 \pm 2.115$ & $-2.329^{*}$ \\
\hline & & Non-dominant eye & $6.426 \pm 2.169$ & $4.944 \pm 1.728$ & -1.996 \\
\hline & & Binocular viewing & $8.043 \pm 3.185$ & $6.272 \pm 1.944$ & -1.726 \\
\hline \multirow{6}{*}{ 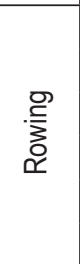 } & \multirow{3}{*}{$\begin{array}{c}\text { Peripheral } \\
\text { location }\end{array}$} & Dominant eye & $5.849 \pm 1.854$ & $3.838 \pm 1.155$ & $2.794^{*}$ \\
\hline & & Non-dominant eye & $5.475 \pm 1.369$ & $3.936 \pm 1.292$ & $2.510^{*}$ \\
\hline & & Binocular viewing & $5.597 \pm 1.726$ & $3.787 \pm 1.309$ & $2.549^{*}$ \\
\hline & \multirow{3}{*}{$\begin{array}{l}\text { Central } \\
\text { location }\end{array}$} & Dominant eye & $6.203 \pm 2.465$ & $4.133 \pm 1.763$ & 2.082 \\
\hline & & Non-dominant eye & $5.748 \pm 2.430$ & $3.554 \pm 1.663$ & $2.268^{*}$ \\
\hline & & Binocular viewing & $6.686 \pm 3.173$ & $4.444 \pm 1.945$ & 1.829 \\
\hline \multirow{6}{*}{$\begin{array}{l}\overline{\overline{0}} \\
\frac{0}{\overline{0}} \\
\frac{\overline{0}}{>}\end{array}$} & \multirow{3}{*}{$\begin{array}{c}\text { Peripheral } \\
\text { location }\end{array}$} & Dominant eye & $6.060 \pm 1.600$ & $4.481 \pm 1.524$ & $2.234^{*}$ \\
\hline & & Non-dominant eye & $5.540 \pm 1.352$ & $3.743 \pm 1.273$ & $3.021^{* \star}$ \\
\hline & & Binocular viewing & $5.567 \pm 2.097$ & $4.131 \pm 1.812$ & 1.600 \\
\hline & \multirow{3}{*}{$\begin{array}{l}\text { Central } \\
\text { location }\end{array}$} & Dominant eye & $6.329 \pm 1.684$ & $3.621 \pm 2.031$ & $3.310^{\star *}$ \\
\hline & & \begin{tabular}{|l|} 
Non-dominant eye \\
\end{tabular} & $5.961 \pm 1.872$ & $3.541 \pm 1.514$ & $3.078^{* *}$ \\
\hline & & Binocular viewing & $6.640 \pm 2.732$ & $4.332 \pm 1.804$ & $2.111^{*}$ \\
\hline
\end{tabular}


viewing ( $\mathrm{p}<0.01)$, non-dominant eye viewing $(\mathrm{p}<0.01)$, and binocular viewing $(\mathrm{p}<0.05)$ during stimulation of the central location. As far as the peripheral location is concerned, significantly lower values of this parameter were observed in subjects who had been training volleyball for a longer time, for the stimulation of both the dominant $(\mathrm{p}<0.05)$ and non-dominant eye $(\mathrm{p}<0.01)$.

\section{P100 wave latency}

Significant intra-group differences $(p>0.05)$ were not observed in the variability of VEP P100 latency with relation to training experience in any of the sports disciplines examined. In the case of the results obtained for the boxers for the peripheral location in the non-dominant eye, the differences bordered on statistical significance, indicating a shorter latency of the P100 wave in athletes with greater training experience compared to the remaining athletes $(104.066 \pm 3.003 \mathrm{~ms}$ vs. $106.526 \pm$ $4.010 \mathrm{~ms}$, respectively; $\mathrm{p}=0.078$ ). In the group of rowers, there was a somewhat longer mean P100 latency in less experienced athletes than in more experienced ones $(109.511 \pm 5.551 \mathrm{~ms}$ vs. $105.310 \pm 3.358$, respectively; $p=0.059)$, and in their case, the difference was also almost statistically significant.

\section{Discussion}

The aim of the study was to assess the visual evoked potentials in athletes practising different sports disciplines with varying training experience. The hypothesis formulated in the study that more experienced subjects would be characterised by a greater effectiveness of visual processing was confirmed only for some of the VEP parameters which were examined.

The assessment of the parameters of the P100 wave in athletes with varying training experience showed significantly lower values of P100 amplitude for the peripheral and central locations in monocular and binocular viewing for more experienced volleyball players. Likewise, Özmerdivenli et al. [9] found a significantly lower amplitude and shorter latency of the N145 wave of visual evoked potentials in volleyball players compared with untrained subjects. The results obtained in the current study revealed similar relationships in the group of rowers with respect to the peripheral location (for monocular and binocular viewing) and boxers (for the dominant eye in the central location). This would mean that training not only sports with high perceptual demands, such as volleyball or boxing, can modulate the visual signal. Thus, the results of the current study did not confirm the hypothesis that variability in the bioelectric function in the visual pathway resulting from training experience is interrelated with the perceptual requirements stemming from the specificity of a particular sporting activity.

VEP amplitude values are considered to indicate the functional number of nerve cells which are activated when the visual signal is being transmitted. Clinical studies have demonstrated a positive correlation between the thickness of nerve fibre layers and the value of VEP amplitude in patients diagnosed with optic neuritis [17]. One of the elements influencing the value of the VEP amplitude is the capacity to maintain a heightened level of vigilance. In the experimental research carried out by Clark and Hillyard [18], subjects were stimulated using spatial stimuli (in the left and right visual fields) during standard recording of VEP. The mechanisms of selected attention which were activated when the subjects were presented with spatial stimuli were observed in secondary visual areas. The amplitudes of the P100 and N145 waves were higher during stimulation with spatial stimuli compared to standard stimulation. In another electro- physiological study, involving athletes, Taliep et al. [19] analysed the latency and amplitude of the P300 wave (an electrophysiological indicator of attention) in a group of cricket players as they were shown video footage of the flight trajectories of balls thrown using different techniques. The study showed that less skilled batsmen were characterised by a higher amplitude of the $\mathrm{P} 300$ wave, longer reaction time, and poorer results in recognising the type of technique used to deliver the ball. The authors suggested that recognising the type of throwing technique required less involvement of attention processes in athletes with a higher skill level compared to those with a lower one. This would indicate a greater effectiveness of the processes of discriminating specific stimuli in athletes with considerable experience and a high level of achievement. As far as the results of the current study are concerned, it can be presumed that the technique of pattern stimulation used during the VEP test did not engage the attention processes of the more experienced subjects to such an extent as was the case with less experienced athletes. The results suggest that if more specific patterns had been used, the differences might have been more clearly observable.

As for the latency of the P100 wave, the current study did not find statistically significant differences in the values recorded in either of the disciplines in athletes with varying training experience. Earlier research has shown, however, that sports training can have a significant impact on reducing P100 latency. Such were the findings of Zhao et al. [13], who reported a reduction in this parameter $(\mathrm{p}<0.05)$ after 6 -week cycloergometric exercise training, 8-week tennis training, and 6-week aerobic exercise training, although their study did not confirm the impact of Qigong training on changes in this VEP parameter. Thus the results of that study would indicate that dynamic forms of physical activity contribute to better visual pathway function. In another study, while assessing the VEP P100 wave, Zwierko et al. [2] found a reduction in the time required to transmit the visual signal during a 2-year period of training in a group of eleven female volleyball players. When it comes to the results of the current study, it is possible that the lack of differences in this VEP parameter between athletes with more and less training experience is due to the athletes' early sensory adaptation to the conditions determined by the specificity of the sports training.

It needs to be mentioned that the issue of the impact of different levels of training experience on the adaptations of perceptual functions has been researched only scarcely to date. So far researchers have mainly focused on investigating visual evoked potentials in groups of athletes and untrained individuals. The differences found for the parameters of the visual evoked potentials between professional athletes and non-athletes have indicated that adaptations of the visual functions in sports requiring rapid detection of and response to visual stimuli are possible $[1,8,9,12]$. The results of studies carried out by other authors have confirmed the influence of long-term sports training characterised by a high degree of involvement of perceptual functions on neuroanatomical changes in the brains of athletes practising different sports disciplines. For example, Jacini et al. [20] observed a higher volume of grey matter tissue in the frontal lobe in the prefrontal cortex region in judo athletes compared with the control group. Changes in grey matter volume were also found for the group of judo athletes in the middle and inferior gyri of the temporal lobe including the paralimbic areas as well as in the parietal and occipital lobes. Similar results were obtained by Park et al. [21] in a study involving basketball players. The changes observed concerned the region of the cerebellum and its sensitivity to professional basketball training. 
Undoubtedly, neural adaptations stemming from undertaking sports training are an interesting research topic which requires further investigation.

\section{Conclusions}

1. Training experience does have an influence on the early stage of sensory processing with respect to neural activity. In most of the groups of athletes examined in the study, subjects with greater training experience were characterised by a lower value of the P100 wave amplitude of visual evoked potentials, and thus lower neural activity recorded at the level of the visual cortex.

2. Training experience differentiates athletes with respect to the temporal parameters of the visual evoked potentials elicited using the methods applied in the current study only to a limited extent.

3. The findings of the study indicate that there is no relationship between the modulation of the bioelectric function in the visual pathway resulting from training experience and the perceptual demands specific for a particular sporting activity.

\section{Literature}

1. Jin H., Xu G., Zhang J.X., Ye Z., Wang S., Zhao L. et al. (2010). Athletic training in badminton players modulates the early $\mathrm{Cl}$ component of visual evoked potentials: A preliminary investigation. International Journal of Psychophysiology 78, 308-314. DOI: 10.1016/j.ijpsycho.2010.09.005.

2. Zwierko T., Lubiński W., Lesiakowski P., Steciuk H., Piasecki L., Krzepota J. (2014). Does athletic training in volleyball modulate the components of visual evoked potentials? A preliminary investigation. Journal of Sports Science 32(16), 1519-1528. DOI: 10.1080/02640414.2014.903334

3. Dustmann R.E., Ruhling R.O., Russell E.M., Shearer D.E., Bonekat W., Shigeoka J.W. et al. (1984). Aerobic exercise training and improved neuropsychological function of older adults. Neurobiology of Aging 5(1), 35-42. DOI: 10.1016/0197-4580(84)90083-6.

4. Di Russo F., Pitzalis S., Spitoni G., Aprile T., Patria F., Spinelli D. et al. (2005). Identification of the neural sources of the pattern-reversal VEP. NeuroImage 24(3), 874-886. DOI: 10.1016/j.neuroimage.2004.09.029

5. Bonmassar G., Schwartz D.P., Liu A.K., Kwong K.K., Dale A.M., Belliveau J.W. (2001). Spatiotemporal brain imaging of visual-evoked activity using interleaved EEG and fMRI recordings. NeuroImage 13, 1035-1043. DOI: 10.1006/ nimg.2001.0754.

6. Onofrj M., Fulgente T., Thomas A., Curatola L., Peresson M., Lopez L. et al. (1995). Visual evoked potentials generator model derived from different spatial frequency stimuli of visual field regions and magnetic resonance imaging coordinates of V1, V2, V3 areas in man. International Journal of Neuroscience 83, 213-239. DOI: 10.3109/00207459508986340.

7. Thomas N.G., Harden L.M., Rogers G.G. (2005). Visual evoked potentials, reaction times and eye dominance in cricketers. The Journal of Sports Medicine and Physical Fitness 45, 428-433.
8. Delpont E., Dolisi C., Suisse G., Bodino G., Gastaud M. (1991). Visual evoked potentials: Differences related to physical activity. International Journal of Sports Medicine 12, 293-298. DOI: 10.1055/s-2007-1024684.

9. Özmerdivenli R., Bulut S., Bayar H., Karacabey K., Ciloglu F., Peker I. et al. (2005). Effects of exercise on visual evoked potentials. International Journal of Neuroscience 115, 1043-1050. DOI: 10.1080/00207450590898481.

10. Zwierko T., Lubiński W., Lubkowska A., NiechwiejSzwedo E., Czepita D. (2011). The effect of progressively increased physical efforts on visual evoked potentials in volleyball players and non-athletes. Journal of Sports Sciences 29, 1563-1572. DOI: 10.1080/02640414.2011.605166.

11. Taddei F., Viggiano M.P., Mecacci L. (1991). Pattern reversal visual evoked potentials in fencers. International Journal of Psychophysiology 11, 257-260. DOI: 10.1016/01678760(91)90019-T.

12. Del Percio C., Brancucci A., Vecchio F., Marzano N., Pirritano M., Meccariello E. et al. (2007). Visual event-related potentials in elite and amateur athletes. Brain Research Bulletin 74, 104-112. DOI: 10.1016/j.brainresbull.2007.05.011.

13. Zhao J.G., Pang S.J., Che G.W. (2009). Specificity and sensitivity of visual evoked potentials P100 latency to different events exercise. Health 1, 47-50. DOI: 10.4236/health.2009.11009.

14. Williams A.M. (2002). Perceptual and cognitive expertise in sport. The psychologist 15(8), 416-417.

15. Erickson G. (2007). Sports vision: Vision care for the enhancement of sports performance. St. Louis, Mo. USA: Butterworth-Heinemann.

16. Odom J.V., Bach M., Brigell M., Holder G.H., McCulloch D.L., Tormene A.P. et al. (2010). ISCEV standard for clinical Visual Evoked Potentials Standard (2009 update). Documenta Ophthalmologica 120, 111-119. DOI: 10.1007/s10633-0169553-y.

17. Klistorner A., Arvind H., Garrick R., Graham S., Paine M., Yiannikas C. (2010). Inter-relationship of optic coherence tomography and multifocal visual-evoked potentials after optic neuritis. Investigative Ophthalmology and Visual Science 51, 2770-2777. DOI: 10.1167/iovs.09-4577.

18. Clark V.P., Hillyard S.A. (1996). Spatial selective attention affects early extrastriate but not striate components of the visual evoked potential. Journal of Cognitive Neuroscience 8(5), 387-402. DOI: 10.1162/jocn.1996.8.5.387.

19. Taliep S.M., St Clair G.A., Gray J., Van der Merwe L., Vaughan C.L., Noakes T.D. et al. (2008). Event-related potentials, reaction time, and response selection of skilled and less-skilled cricket batsmen. Perception 37, 96-105. DOI: $10.1068 / \mathrm{p} 5620$.

20. Jacini W.F., Cannonieri G.C., Fernandes P.T., Bonilha L., Cendes F., Li L.M. (2009). Can exercise shape your brain? Cortical differences associated with judo practice. Journal of Science and Medicine in Sport 12(6), 688-690. DOI: 10.1016/j.jsams.2008.11.004.

21. Park I.S., Lee K.J., Han J.W., Lee N.J., Lee W.T., Park K.A. et al. (2009). Experience-dependent plasticity of cerebellar vermis in basketball players. Cerebellum 8(3), 334-339. DOI: 10.1007/s12311-009-0100-1.

Submitted: January 27, 2017

Accepted: April 26, 2017 